\title{
Report
}

\section{Global Dryland Ecosystem Programme (G-DEP): Africa consultative meeting report}

\author{
PENG Yu ${ }^{1,2}$, FU Bojie ${ }^{2,3}$, ZHANG Linxiu ${ }^{2,4}$, YU Xiubo ${ }^{1,2}$, FU Chao ${ }^{1,4}$, Salif DIOP ${ }^{5}$, Hubert \\ HIRWA $^{1,2}$, Aliou GUISSE ${ }^{6}$, LI Fadong ${ }^{1,2^{*}}$ \\ ${ }^{1}$ State Key Laboratory of Ecosystem Network Observation and Modeling, Institute of Geographic Sciences and Natural \\ Resources Research, Chinese Academy of Sciences, Beijing 100101, China; \\ ${ }^{2}$ University of Chinese Academy of Sciences, Beijing 100049, China; \\ ${ }^{3}$ State Key Laboratory of Urban and Regional Ecology, Research Center for Eco-Environmental Sciences, Chinese Academy of \\ Sciences, Beijing 100085, China; \\ ${ }^{4}$ International Ecosystem Management Partnership, United Nations Environment Programme, Beijing 100101, China; \\ ${ }^{5}$ National Academy of Sciences of Senegal, P.O. Box 4344 Dakar RP, Senegal; \\ ${ }^{6}$ Faculty of Science and Technology, University Cheikh Anta Diop of Dakar, P.O. Box 5005 Dakar-Fann, Senegal
}

\begin{abstract}
In order to enhance and restore the ecosystems of natural capital in African arid regions, the Global Dryland Ecosystem Programme (G-DEP) consultative meeting was hosted in Dakar, Senegal, from 23 to 25 September 2019. This paper details the first African meeting of the G-DEP. Consultative meeting reviewed preceding dryland ecosystems case studies, identified vulnerable arid and semi-arid regions, and proposed sustainable solutions to problems. It also identified the successes and failures of previous attempts to improve vulnerable ecosystems and ultimately formed an action plan to improve these attempts. Climate, ecosystems, and livelihoods for Sustainable Development Goals (SDGs), Great Green Wall Initiative (GGWI) for Sahara and Sahel, and China-Africa cooperation on science, technology, and innovation are three extra main sections concerned of the meeting. Separately, more specific topics as the complicated relationship between these natural processes and human activity, including pastoralism, soil restoration, and vegetation regenerate techniques, were fully discussed. Consultative meeting also identified the positive effects international collaboration can have on dryland regions, specifically in the capacity of sharing information, technology, and innovation on purpose to develop a joint proposal for long-term research programs in African arid and semi-arid areas. Moreover, meetings that review the progress made on ecosystem management for the sustainable livelihoods in Africa, identification of priority areas, and the development and implementation of ecosystem programs for proper research and collaboration in African arid and semi-arid zones, have been proposed as strategic recommendations to enhance the global partnership for sustainable development. Furthermore, as the outcomes of the workshop, there are three steps proposed to handle African dryland climate changes, several aspects suggested to solve current dilemmas of the GGWI, and a series of actions recommended for G-DEP related activities in Africa.
\end{abstract}

Keywords: Africa; Global Dryland Ecosystem Programme (G-DEP); dryland; ecosystem; consultation; Sustainable Development Goals; Great Green Wall Initiative (GGWI)

Citation: PENG Yu, FU Bojie, ZHANG Linxiu, YU Xiubo, FU Chao, Salif DIOP, Hubert HIRWA, Aliou GUISSE, LI Fadong. 2020. Global Dryland Ecosystem Programme (G-DEP): Africa consultative meeting report. Journal of Arid Land, 12(3): 538544. https://doi.org/10.1007/s40333-020-0056-z

*Corresponding author: LI Fadong (E-mail: lifadong@igsnrr.ac.cn)

Received 2020-04-30; revised 2020-05-21; accepted 2020-06-02

(C) Xinjiang Institute of Ecology and Geography, Chinese Academy of Sciences, Science Press and Springer-Verlag GmbH Germany, part of Springer Nature 2020 


\section{Introduction}

Land cover records both natural and human activities. In particular, the drylands cover over $45 \%$ of the Earth's surface (Huang et al., 2016) and are home to more than $38 \%$ of the global population comprising up to $2 \times 10^{9}$ inhabitants. The drylands are especially vulnerable to aridity and climate change (Berdugo et al., 2020). Although arid lands are diverse, with innovative populations in the face of hostile and challenging environments, these drylands are particularly sensitive to rapid social and physical changes (Cervigni et al., 2016). Environmental and socio-demographical impacts particularly jeopardize the livelihoods of these populations, which are often locally, especially in Africa. These rapidly growing impacts include global environmental changes, changing demographics, and arid and semi-arid area degradation (Yao et al., 2020) as well as those on access to water, energy, land, sustainable agriculture, and human and livestock health (Schimel, 2010; FAO, 2016). These constitute the root causes of growing unrest and economic instability at the regional and global levels. To alleviate these challenges, local communities and institutions, as well as global political systems, must be innovative. With the support of research, semi-arid and arid areas could be altered to improve resiliency and avoid unpredictable, increasingly catastrophic disruptions in the future.

Africa has the most extensive dryland system on Earth, accounting for almost $23 \times 10^{6} \mathrm{~km}^{2}$ or approximately $15 \%$ of the global land area (Prăvălie, 2016). However, significant environmental perturbations, especially desertification and other ecological and climatic disturbances, are threatening these drylands. This can cause problems in anthropogenic systems, such as escalating poverty, food insecurity, poor infrastructure, regional conflicts, and political instability. Therefore, ensuring the sustainability of ecosystems and improving the livelihood of the local population in the drylands is essential for sustainable development in Africa. This consultative meeting aims to create a permanent partnership system for dryland sustainability, by providing practical information to the Global Dryland Ecosystem Programme (G-DEP) during its initial phase of implementation in Africa. This consultative meeting also aims to assist in identifying approaches to sustainable agriculture and renewable energy in arid and semi-arid countries of the Sahel region.

The United Nations Environment Programme-International Ecosystem Management Partnership (UNEP-IEMP) and the National Academy of Sciences and Technology of Senegal (ANSTS) jointly organized the first G-DEP consultative meeting in Africa. This workshop aimed to develop a joint proposal for long-term research programmes in arid and semi-arid areas with the goal to answer the following questions:

(1) How can the Sahel region overcome the research gaps for the African dryland ecosystem under the joint framework?

(2) What actions hold importance for the sustainable development in arid and semi-arid regions of Senegal in particular, and Africa in general?

More than 100 participants from China, Africa, the United States, Netherland, France, and other regions of the world attended the G-DEP consultative meeting in Dakar, Senegal, from 23 to 25 September 2019.

\section{Arid and semi-arid ecosystems in Africa}

Africa is almost exclusively experiencing severe changes towards drier conditions, which contrasts the rest of continents in the world; the northern, eastern, and southern regions of Africa are the main three epicentres of drylands transformation (Prăvălie et al., 2019). Impacted by the local natural conditions and global environmental changes, these regions are more prone to land degradation, natural hazards, and water and food shortages (Li et al., 2018; Lu et al., 2018). Researchers shared their latest implemented work in Africa's arid and semi-arid regions.

A case study in South Africa showed that new land cover classification approaches, based on Landsat 8 OLI, Sentinel-1, and SRTM (Shuttle Radar Topography Mission), yield eminent adaptability and practicality in the Nzhelele and Levhuvu catchments. The fraction of tree cover, shrub cover, grassland, cropland, aquatic vegetation, sparse vegetation, bare areas, built up, open 
water, and plantation cover are $16.47 \%, 35.55 \%, 15.63 \%, 13.07 \%, 0.11 \%, 12.50 \%, 1.42 \%, 4.06 \%$, $0.48 \%$, and $1.25 \%$, respectively (Zeng et al., 2020). Currently, nearly $60.00 \%$ of South Africa's land has been degraded. Therefore, land degradation, especially in the form of soil erosion, is a major concern (Musakwa et al., 2020). Land cover products from arid and semi-arid areas play a critical role in improving the performance of ecosystem, hydrology, and climate change studies, and such products are fundamental requirements to understand the complex interactions between human activities and global environmental change (Khan et al., 2019). Landscape changes in the Nzhelele and Levuvhu catchments have considerable agricultural and economic importance. They are located in a semi-arid region where precipitation is the main limiting factor. The catchment case study indicates that land cover is a mixture with shrubland, grassland, cropland, and settlements as well as areas where the land cover has changed considerably due to intensive human activities.

Apart from landscape alteration, policy acts as another key to ecosystem solution. Research in the Ferlo Desert in Senegal has shown that government decentralization policies allow regional communities to share specific capabilities with the State, including those related to land use planning and natural resource management. Public decentralization policies also enable its current potential values, such as pastoral hydraulics. In the Ferlo Desert, due to the variable climate, studies of diversity, equitability, and similarity in this area revealed that a buffer zone and a transition area, which are subject to multiple uses by humans, present a greater variety and a higher level of woodland organization than the central location (Bastin et al., 2016). The woody flora inventoried in the Sahel (Ferlo) region is rich in species, with 35 species divided into 27 kinds belonging to 19 families, where the Combretaceae, Mimosaceae, and Caesalpiniaceae are regarded as dominant taxa. The woody stands of Balanites aegyptiaca and Sclerocarya birrea are two wild edible fruit trees that constitute good sources of food wealth in the local area. Other advances are related to non-transmitted diseases caused by the dryland ecosystem degradation. Chronic non-transmitted disease (CNTD) kills nearly $41 \times 10^{6}$ people each year, which is equivalent to seven out of ten people in the world, and are a major threat to health, especially in sub-Saharan Africa, where CNTD tends to be long-lasting and results from a combination of genetic, physiological, environmental, and behavioural factors.

To address these concerns, international cooperation, i.e., the G-DEP, was proposed. The overall objectives of the G-DEP are to understand the response of dryland ecosystems to global environmental change and to elucidate methods for fostering the development of pathways to support increasing the resilience of socio-ecological systems and the sustainable development in dryland ecosystems (Feng et al., 2020a). Specifically, the goal is to quantify the magnitude and direction of change and the associated responses of dryland ecosystems to the land system and social process and to identify factors controlling the vulnerability and resilience of dryland ecosystems as well as to understand the impact of global environmental change on ecosystem services. To accomplish these goals, the G-DEP is conducting targeted regional studies in arid regions around the world. Drylands research in Australia constitutes the latest example (Feng et al., 2020b). In African arid and semi-arid ecosystems, there are four further research themes needed to focus on: (1) impacts of climate change to dryland regions; (2) interactions between social and ecological systems; (3) improvement of ecosystem services and poverty eradication; and (4) prevention of dryland degradation and ecosystem restoration.

\section{Climate, ecosystems, and livelihoods for Sustainable Development Goals (SDGs) in Africa}

Insufficient research on the climate and livelihoods in arid and semi-arid ecosystems has been an ongoing issue in Africa (Zhang et al., 2018). If ecosystem management is not well done and sustainable, impacts on the ecosystems, as well as the consequences on biodiversity and human well-being, can be enormous (Wei et al., 2018).

In the Sahel region, increased rainfall has had a positive effect on vegetation cover, the general trend of which indicates changes in the variation of the vegetation index. This "re-greening" phenomenon has been accompanied by an improvement in the quality of land in the region 
(Tounkara et al., 2020). In Zimbabwe, a perception survey (Perception and Indigenous Knowledge Systems) was conducted among 3000 farmers in 8 districts over a two-year period on topics such as population perception on increasing air temperature, shorter winter, reduced rainfall, extended dry season, and increasing frequency of droughts. The results showed that climate change resulted in an increase in temperature in all districts with climate variability (Gwenzi et al., 2020). In Rwanda, although rainfall has been declining, there was an upsurge of floods in recent decades, which indicated the variability of the climatic regime (Mugabowindekwe et al., 2018). In semi-arid zones, pastoralism is also becoming vulnerable. Research in Senegal, Benin, and Mali indicated that water constitutes the major constraint whereas other constraints include governance barriers, public policy vulnerabilities, and the weak dynamism of collective actions that are detrimental to improve pastoralism.

In the particular case of Africa, the context of demographic growth and rising temperatures concerning climate change amplify the development of extreme events. Currently, there are three steps in place to handle the situation: (1) calculation of gross risk; (2) determination of gradual risk; and (3) classification to understand the deviations that may occur.

Determining the areas at risk and assessing areas that will be affected have received good feedbacks in China (Feng et al., 2020a). Water, in particular, is a critical factor. It is necessary to link research on the water to the sustainability of the human-nature system (Rohatyn et al., 2018). China has the experience of applying integrated water analyses, and the relationship between downstream water use and upstream water supply is an essential aspect of this analysis. Water transfer and change between the rainwater consumption of the natural ecosystem, rainwater consumption of cropland, and irrigated water consumption from irrigated cropland need to be understood. Considering that African countries present similar dryland situations, if the results of research on the agro-ecosystems in Ethiopia are conclusive (Song et al., 2018), it may be possible to replicate them in other countries, like Senegal (Niang et al., 2019).

\section{Great Green Wall Initiative (GGWI) in the Sahara-Sahel region}

The Great Green Wall is an African-led initiative with the goal of rehabilitating an $8000 \mathrm{~km}$ natural wonder of the world across the entire width of Africa with vegetation cover. This initiative is located in Africa's Sahel region, at the southern edge of the Sahara Desert. The GGWI is based on a clear vision with four phases: a start-up phase, an operation phase, a consolidation phase, and a phase of the sustainability of achievements, with the slogan "made by and for the people". This vision and its variations based on differentiated strengths have made concrete achievements on the ground despite the financial constraints it faces. These achievements include Sustainable Land Management (SLM), socio-economic development of the regions concerned, and the reinforcement of the skills of populations in the targeted areas.

Selected Niger as a case study, its Natural Assisted Regeneration (NAS) achieved the goal of the potential rapid replenishment of vegetation cover at a lower cost. The NAS can also be an effective option to implement the GGWI in the Sahara-Sahel region (Moustapha, 2019).

With the installation of the GGWI, dietary changes are increasing in local populations as the administration of the GGWI offers jobs to locals, which increases their purchasing power and subsequently, their ability to diversify food. Previously, pastoralists in the area had frugal diets consisting of milk, millet, curd, cowpeas, and balance oil as well as tea and sugar. Currently, rice has replaced millet, and vegetables and dried fish have been introduced to the diet. These dietary changes will ultimately have an impact on the health of the population.

The Sahel region is home to a rich diversity of migratory bird species that travel over long distances. Due to a loss of the habitats of these migratory birds, the bird population has been declining over the last 40 years. Land degradation in the Sahel region played an essential role in this decline. While the GGWI and other initiatives are working on the restoration of the Sahelian ecosystems and the services they provide, positive changes in the environment can be reflected by the return of Palearctic migratory birds and other local birds.

Based on these case studies, the current dilemmas of the GGWI that need to be solved are mainly 
focused on the following aspects: (1) how to share experiences from the GGWI initiative with other countries?; (2) the primary agroforestry approach of the GGWI tends to leave aside other aspects of the socio-ecological system; (3) is there a need to integrate the other countries of Lake Chad to improve coherence?; (4) improving the success rates of reforestation and afforestation activities in the GGWI; (5) the assessment of the value of pastoralism needs to be accepted seriously by the GGWI; (6) the mobilization of financial resources and the existence of a fundraising strategy; (7) the availability of water resources and the profiling of biological diversity and its usefulness; (8) the existence of a monitoring and evaluation system; (9) the need for a technology transfer system from China; (10) governance bodies; and (11) the governance systems (local as well as regional).

\section{China-Africa cooperation on science, technology, and innovation}

Since the $1^{\text {st }}$ Conference on Climate, Ecosystems, and Livelihoods in Nairobi, Kenya, in 2017, significant progress has been made to strengthen the China-Africa partnership as well as the SouthSouth Cooperation and multilateral cooperation on sustainable development issues in Africa. Fundamental research in China envisions long-term programmes with policy and spatial coherence. Establishing operational and practical cooperation with China is more than an adequate pathway to consolidate the achievements of the sustainable management of dryland ecosystems and resources. China-Africa collaborations on science, technology, and innovation in dryland ecosystems are expected to yield significant benefits to both the G-DEP and GGWI.

Collaboration between China and Africa can be achieved at two levels. At the individual level, researchers are allowed to identify and propose opportunities with Chinese partners; and at the institutional level, research is conducted by national or regional institutions.

Different priority opportunities for collaboration exist between China and Africa, notably on livestock sectors and pastoralism, soil restoration techniques, vegetation regeneration techniques, water resources, renewable energies, and bushfire management.

For G-DEP related activities in Africa, the recommended actions are as follows:

(1) Collecting and sharing various information and data on the environment, socio-economy, and land for the drylands programme in particular.

(2) Disseminating many different solutions offered by satellite imagery in Africa.

(3) Collecting data and improving model for the monitoring of ecosystems and ecosystem services.

(4) Developing joint case studies with China in the socio-economic field.

(5) Transferring innovations and technologies developed in Xinjiang Uygur Autonomous Region of China to the GGWI.

(6) Establishing long-term mechanisms of observations, monitoring, and ecosystem management.

(7) Developing predictive or forecasting models for natural disaster and risk management.

(8) Rewarding research results that can jointly serve as a global contribution to the sustainable management of drylands.

(9) Creating an African Institute of Arid Areas (affiliated with African research networks).

(10) Integrating ecological, socio-economic, legal, and governance aspects to address poverty aspects of local communities.

\section{Conclusions}

Based on the current status of African dryland ecosystems, the restoration and enhancement of the natural capital of the GGWI for the Sahel region should be based on the reliable scientific knowledge and information. Given the similarities with some arid areas of China, particularly the Xinjiang, the sharing of innovations and technologies developed by the G-DEP towards sustainable management, long-term ecosystem monitoring and evaluation enhancement, and the protection of agro-sylva-pastoral systems adapted to drylands is recommended.

Consultative meetings that review the progress made on ecosystem management for the sustainable livelihoods in Africa, identification of priority areas, and the development and 
implementation of ecosystem programmes for proper research and collaboration in African arid and semi-arid areas, have been proposed as strategic recommendations to enhance the global partnership for sustainable development.

Furthermore, meetings and workshops aimed at developing a joint proposal for long-term research programmes on African arid and semi-arid areas with clear goals, objectives, and outputs have been identified as successful cooperation opportunities. In addition, during the launch of the G-DEP programme, participants should focus more on creating a permanent China-Africa partnership mechanism as an active international collaborative programme.

\section{Acknowledgements}

Funding to support this consultative meeting was provided by the National Natural Science Foundation of China (41761144053, 41661144022) and the International Partnership Program of Chinese Academy of Sciences (121311KYSB201700). We thank UN Environment-International Ecosystem Management Partnership (UNEPIEMP) and the National Academy of Sciences \& Techniques of Senegal (ANSTS) for their contributions in organizing and hosting this consultation, in Dakar, Senegal, as well as the University Cheikh Anta Diop of Dakar. Likewise, we thank The World Academy of Sciences (TWAS) and the Division of International Organization Programmes, Bureau of International Cooperation, Chinese Academy of Sciences for their constructive comments and supports during this consultative meeting.

\section{References}

Bastin J-F, Berrahmouni N, Grainger A, et al. 2016. The extent of forest in dryland biomes. Science, 356(6338): 635-638.

Berdugo M, Delgado-Baquerizo M, Soliveres S, et al. 2020. Global ecosystem thresholds driven by aridity. Science, 367(6479): 787-790.

Cervigni R, Morris M. 2016. Confronting Drought in Africa's Drylands: Opportunities for Enhancing Resilience. Washington: World Bank Publications, 35-89.

FAO (Food and Agriculture Organization of the United Nations). 2016. Trees, Forests and Land Use in Drylands: The First Global Assessment, Preliminary Findings. Rome: FAO, 1-31.

Feng Q, Zhao W W, Hu X P, et al. 2020a. Trading-off ecosystem services for better ecological restoration: A case study in the Loess Plateau of China. Journal of Cleaner Production, 257: 120469, doi: 10.1016/j.jclepro.2020.120469.

Feng X M, Stafford-Smith M, Zhang L, et al. 2020b. Global Dryland Ecosystem Programme (Global-DEP): Australasian consultation report. Journal of Soils and Sediments, 20(3): 1807-1810.

Gwenzi J, Mashonjowa E, Mafongoya P. 2020. A participatory approach to developing community based climate services in Zimbabwe: A case study of Uzumba Maramba Pfungwe (UMP) district. In: Handbook of Climate Services. Switzerland: Springer International Publishing, 447-462.

Huang J, Yu H, Guan X, et al. 2016. Accelerated dryland expansion under climate change. Nature Climate Change, 6: $166-171$. Khan A S, Yi H, Zhang L X, et al. 2019. An integrated social-ecological assessment of ecosystem service benefits in the Kagera River Basin in Eastern Africa. Regional Environmental Change, 19(1): 39-53.

Li F D, Leng P F, Zhang Q Y, et al. 2018. Understanding agriculture production and food security in Ethiopia from the perspective of China. Journal of Resources and Ecology, 9(3): 237-249.

Lu N, Wang M Y, Ning B L, et al. 2018. Research advances in ecosystem services in drylands under global environmental changes. Current Opinion in Environmental Sustainability, 33: 92-98.

Moustapha I S. 2019. Characterization of natural pastures in Niger: Diversity and methods of exploitation-bibliographic synthesis. Environmental and Water Sciences, Public Health and Territorial Intelligence, 3(3): 181-191.

Mugabowindekwe M, Muyizere A, Li F D, et al. 2018. Application of multi-temporal MODIS NDVI data to assess practiced maize calendars in Rwanda. Journal of Resources and Ecology, 9(3): 273-280.

Musakwa W, Wang S, Wei F L, et al. 2020. Survey of community livelihoods and landscape change along the Nzhelele and Levuvhu river catchments in Limpopo Province, South Africa. Land, 9(3): 91, doi: 10.3390/land9030091.

Niang A, Scheren P, Diop S, et al. 2019. The Senegal and Pangani rivers: Examples of over-used river systems within waterstressed environments in Africa. In: Wolanski E W, Day J, Elliott M, et al. Coasts and Estuaries. Amsterdam: Elsevier Press, 311-320.

Prăvălie R. 2016. Drylands extent and environmental issues. A global approach. Earth-Science Reviews, 161: $259-278$.

Prăvălie R, Bandoc G, Patriche C, et al. 2019. Recent changes in global drylands: Evidences from two major aridity databases. 
Catena, 178: 209-231.

Rohatyn S, Rotenberg E, Ramati E, et al. 2018. Differential impacts of land use and precipitation on "Ecosystem Water Yield". Water Resources Research, 54(8): 5457-5470.

Schimel D. 2010. Drylands in the earth system. Science, 327(5964): 418-419.

Song S, Li F D, Lu Y L, et al. 2018. Spatio-temporal characteristics of the extreme climate events and their potential effects on crop yield in Ethiopia. Journal of Resources and Ecology, 9(3): 290-301.

Tounkara A, Clermont-Dauphin C, Affholder F, et al. 2020. Inorganic fertilizer use efficiency of millet crop increased with organic fertilizer application in rainfed agriculture on smallholdings in central Senegal. Agriculture, Ecosystems \& Environment, 294: 106878, doi: 10.1016/j.agee.2020.106878.

Wei F, Wang S, Fu B J, et al. 2018. Balancing community livelihoods and biodiversity conservation of protected areas in East Africa. Current Opinion in Environmental Sustainability, 33: 26-33.

Yao J, Liu H, Huang J, et al. 2020. Accelerated dryland expansion regulates future variability in dryland gross primary production. Nature Communications, 11(1): 1665, doi: 10.1038/s41467-020-15515-2.

Zeng H W, Wu B F, Wang S, et al. 2020. A synthesizing land-cover classification method based on google earth engine: A case study in Nzhelele and Levhuvu catchments, South Africa. Chinese Geographic Science, 30(3): 397-409.

Zhang L Y, Liu J, Fu C. 2018. Calling for nexus approach: Introduction of the flagship programme on climate, ecosystems and livelihoods. Journal of Resources and Ecology, 9(3): 227-231. 